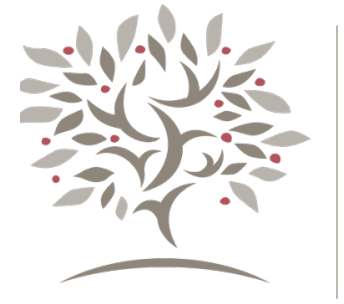

\title{
The Challenges Facing Asian and Asian American Mid-Career Faculty
}

In the summers of 2016 and 2017, the Wabash Center for Teaching and Learning in Theology and Religion sponsored a two-year colloquy for mid-career Asian and Asian American scholars of religion and theology at the Claremont School of Theology in California. The five facilitators and thirteen participants were administrators and faculties at divinity schools, liberal arts colleges, and universities. They discussed mid-career challenges and issues, including teaching, research, career development, mentoring, and the balance of life and work. The colloquy helped participants to reflect on their roles as mid-career faculty, articulate their visions and vocations as teachers and scholars, develop long-term career plans, identify issues in their institutional contexts, and recognize new strategies and resources in their work. It provided a supportive environment for participants to share their vulnerabilities and discuss intricate racial politics in departments of religious studies and seminaries. They also took field trips to Hsi Lai Buddhist Temple and the Jain Center of Southern California. These field visits helped them understand the contributions of Asian religious communities to society and provided the contexts for discussing the relationship between their teaching and research and Asian religious communities. In this forum, we invited five participants to share their reflections on issues facing mid-career faculty.

\section{ABOUT THE AUTHOR}

Kwok Pui Lan is Dean's Professor of Systematic Theology at Candler School of Theology, Emory University, and a past president of the American Academy of Religion. 
